\title{
Process Management 1-2-3: a maturity model and diagnostics tool
}

\author{
Peter Cronemyr and Mikael Danielsson
}

\section{Linköping University Post Print}

\section{Tweet}

N.B.: When citing this work, cite the original article.

This is an electronic version of an article published in:

Peter Cronemyr and Mikael Danielsson, Process Management 1-2-3: a maturity model and diagnostics tool, 2013, Total Quality Management and Business Excellence, (24), 7-8, 933944.

Total Quality Management and Business Excellence is available online at informaworldTM: http://dx.doi.org/10.1080/14783363.2013.791114

Copyright: Taylor \& Francis (Routledge): SSH Titles http://www.routledge.com/

Postprint available at: Linköping University Electronic Press http://urn.kb.se/resolve?urn=urn:nbn:se:liu:diva-96419 


\title{
Process Management 1-2-3
}

\section{- A Maturity Model and Diagnostics Tool}

\author{
Peter Cronemyr \\ Ph.D., Senior Lecturer, Assistant Professor at \\ Quality Technology and Management \\ Linköping University \\ S-581 83 Linköping, \\ Sweden \\ peter.cronemyr@liu.se \\ Mikael Danielsson \\ M.Sc., Process Management Consultant at \\ Propia AB \\ Repslagaregatan 12 \\ S-603 32 Norrköping \\ Sweden \\ mikael.danielsson@propia.se
}




\begin{abstract}
In this paper we provide a insight into process management that offers a hands-on simple method to improve Process Management. Organizations implementing 'some modern' management concept sometimes fail or do not achieve the expected results. From our own industrial experiences, we found that organizations implementing Process Management sometimes start off on a 'too advanced' level without having fulfilled the necessary prerequisites. For that purpose, in this paper, we present a Process Management maturity model developed in an environment of industrial and academic cooperation. In addition to the model we present a diagnostics tool that has been developed together with several companies to be used by organizations to assess their current level of process maturity. By using this it is the purpose that organizations could reduce their risk of starting off 'too high' and thus failing in their efforts.
\end{abstract}

Keywords: Process Management, Process Maturity, Maturity Diagnostics 


\section{Introduction}

Organizations implementing 'some modern' management concept sometimes fail or do not achieve the expected results. According to Beer and Nohria (2000) as many as two thirds of all change initiatives have been reported to end in failure, seemingly regardless of the content of the change (Beer and Nohria, 2000; Sveningsson and Sörgärde, 2007; Langstrand, 2012). The success of different approaches to adopting and implementing management ideas such as Process Management was studied by Hellström (2007). Dahlgaard et.al. (2011) argue that the fundamental principles of TQM need to be in place for any organisational change effort to be successful. Beer and Nohria (2000) suggested a combined approach of organizational change initiatives based on 'hard' economic focus and 'soft' organizational focus. DahlgaardPark (2011) classify this 'hard' focus as a typical Western attitude towards quality management in terms of being short-termed and result-oriented in contrast to the 'soft' focus as a typical Japanese attitude in terms of being long-termed and processoriented. For quality management to be successful, she advocates a combination of the two. From our own industrial experiences, we found that organizations implementing Process Management sometimes start off on a 'too advanced' level without having fulfilled the necessary prerequisites. For that purpose, in this paper, we present a Process Management maturity model developed in an environment of industrial and academic cooperation. In addition to the model we present a diagnostics tool that has been developed together with several companies to be used by organizations to assess their current level of process maturity. By using this it is the purpose that organizations could reduce their risk of starting off 'too high' and thus failing in their efforts. 


\section{Methodology}

This development project was conducted during approximately a decade in accordance with the methodology of a 'collaborative action inquiry' (Westlander, 1998), which seeks to integrate the social sciences with organizational knowledge to generate actionable scientific knowledge. The development work was carried out at a major gas turbine company, where the first author was employed during thirteen years, and several other companies in Swedish industry, where the two authors have carried out assignments and interventions. The basic ideas for the process maturity model were described in the first author's Ph.D. thesis (Cronemyr, 2007). The model was then further developed and completed with the diagnostics tool in the second author's M.Sc. thesis (Bergholtz and Danielsson, 2012).

\section{Theory and previous research}

\section{Process Management}

Focusing on processes was promoted by Shewhart $(1931,1939)$ as a way to achieve quality and satisfied customers. There are many definitions but most used within the quality context are similar to the one given by Bergman and Klefsjö, which is the one we choose to use:

"A process is a network of activities that are repeated in time, whose objective is to create value to external or internal customers.” (Bergman \& Klefsjö, 2010, s. 456)

A process map shows activities as well as relations with suppliers and customers, something that is not equally obvious by looking at a traditional organization chart for an organization without defined processes. One could argue that an organization chart shows 'what you can do' while the process maps show 'what you do' (Cronemyr, 
2007). The first has a tendency to fulfil internal goals, e.g. keeping the budget, while the latter focuses more on external goals like fulfilling customer satisfaction (Melan, 1995; Cronemyr and Witell, 2010).

The ISO 9001 standard requires an organization to apply a process approach to three types of actions: management, product and/or service realisation, and support. Process owners should be appointed who have a defined responsibility and authority to implement, maintain and improve the processes. Documentation of processes should include process objectives, process map/flow chart, procedures and work instructions, quality plans, measurements and audit results, and information on on-going and finished improvements. Goals and measurements of an organization's processes are often gathered and presented in a Balanced Scorecard (Kaplan and Norton, 1992).

The importance of adopting a process view and continuously improving processes has led to the creation of the Process Management philosophy. Bergman and Klefsjö (2010) trace the origins of Process Management back to TQM authorities Shewhart and Juran. Harrington (1991) described the Process Management methodology used at IBM as the following steps:

1. Organizing for improvement

2. Understanding the process

3. Streamlining

4. Measurements and Controls

5. Continuous Improvement

Process Management has been a popular topic in the management literature for at least two decades (Hellström, 2006). In 2002, Michael Hammer - the creator of the ‘BPR manifesto’ (as in Business Process Re-engineering, see Hammer and Champy, 1993) - argued that "Six Sigma should be a part of Process Management, not the 
other way around" (Hammer, 2002, p. 32). The question of how to integrate Six Sigma and Process Management remains though.

Often there is confusion about processes and Process Management. Several failed attempts of introducing Process Management have been caused by the lack of understanding of the basic ideas behind the words, e.g. systems thinking, customer focus and theory of variation, as well as the consequences for management activities (Bergman \& Klefsjö, 2010). It may be difficult to break the organizational thinking patterns when the core processes are to be defined, even for persons with 'process awareness' (Rentzhog, 1998). 'Process awareness', or 'process thinking’, “enables full participation in the change process and a way of establishing current and future performance levels" (Oakland and Tanner, 2007). Oakland and Tanner (2007) conclude that "process management sits at the heart of a successful change programme”.

In research papers (see e.g. Henderson and Evans, 2000; Goldstein, 2001; Pande et. al., 2000; Antony and Banuelas, 2002; Sandholm and Sörqvist, 2002; Schön, 2006; Cronemyr, 2007), 'management commitment' is one of the most commonly mentioned success criteria for implementing new management ideas like Process Management and Six Sigma. However there are few papers mentioning how to practically achieve management commitment in order to implement Process Management successfully (Cronemyr, 2007). Beer (2003) argues that there is often a gap between the management rhetoric about their intentions for TQM and the reality of the implementation of the concept within the company. 


\section{Process Maturity}

By developing and continuously improving processes an organization can reach different maturity levels, as given e.g. by the Capability Maturity Model (CMM) developed by the Software Engineering Institute, from the original ideas by Philip Crosby, described in Paulk et al. (1993). CMM mainly focuses on software development, but there are other maturity models with a business process focus.

Harrington (1991) describes a model for process qualification which is similar to a process maturity model. However it does not describe any specific guidelines how to improve from one qualification level to the next one. The first qualification level can also be considered to be fairly high, which would leave several of our studied processes and organizations outside of the scale. The qualification levels are numbered from 6 to 1 where 1 is the highest qualification level. The levels are (Harrington, 1991):

6. Unknown. This level is assigned to all processes which are not yet assessed.

5. Understood. At this level the process design is understood and operates according to prescribed documentation

4. Effective. The process is systematically measured, streamlining has started, and the end-customer expectations are met.

3. Efficient. The process is streamlined and more efficient

2. Error-free. The process is highly effective (error-free) and efficient. The process is also in statistical control.

1. World-class. The process is world-class and continues to improve. The process is also highly flexible.

McCormack (2007) describes another maturity model which focuses on whole organizations instead of separate processes. The maturity levels are considered to be 
stages which organizations need to pass though in an evolutionary change process. The stages solely focus on the balance between functions and processes in the organization, and do not describe concrete criteria for when a stage is fulfilled or not.

There are four levels in this model (McCormack, 2007):

- Ad-hoc. The processes are unstructured and poorly defined. Traditional functions are in focus

- Defined. The basic processes are defined and mapped. A process aspect is added to the organization, but functions are still in main focus.

- Linked. Process management is now a strategic issue. Goals are set for processes and shared across functions.

- Integrated. Process management is now a part of the organizational culture. Structures and jobs are based on processes and processes are considered equal to traditional functions.

Wheeler (1997) describes a model with different process states, which is similar to a maturity model. This model is mainly based on statistical process control. By describing a process according to whether it is in statistical control or not (called the process dimension) and whether the results meet the customer's expectations or not (called the product dimension), four different states are created.

The first state, where the process is not in control and does not meet the customer's expectations, is called the state of chaos. There is a lot of special-cause variation in this state and the process is constantly changing. Due to this it is very difficult to improve the process, attempts of doing so often distorts the process even more.

The second state, where the process is not in control but meets the customer's expectations, is called the brink of chaos. The customer's expectations are in this state 
met by special efforts and modifications, not by following the process. However, it demands a lot of work, and the work is most often reactive.

The third stage, where the process is in control but does not meet the customer's expectations, is called the threshold state. By removing all special cause variation, i.e. focusing on the process instead of the product, the process will become in control. If the customer's expectations are still not met, the process can be improved or redesigned.

The fourth and last stage, where the process is in control and the customer's expectations are met, is called the ideal state. By keep focusing on the process and eliminating special cause variation as it emerges the process will remain in the ideal state. If not, changing conditions will erode the process and the state is lost.

\section{Diagnostics Tools}

There is very limited information on existing assessment and diagnostics tools. The maturity models described above provides either very complex or very simple methods to assess which level in the model a certain process or organization belongs to. CMM (Paulk et.al., 1993) requires a full scale audit by an assessment team to assess a process. Harrington's (1991) qualification model depends on the process owners who apply for an upgrade of his or her process along with proof of meeting all criteria for the level. McCormack (2007) assesses an organization by conducting a survey among 20-30 key-informants, and compiling the results to a score between 1 and 5. Each maturity level corresponds to an interval in the same scale. 


\section{Proposed Model}

From on our own industrial experiences at several companies, and based on previous research on Process Management, we present a new Process Management maturity model and a diagnostics tool. We found that implementation failures were often caused, not by the implemented method being poor, but the organization trying to implement the method taking on a method 'too high up on the maturity scale', i.e. the organization not being mature enough. By applying the newly developed model and diagnostics tool organizations can reduce the risk of failure.

\section{Process Management 1-2-3}

The basis for the Process Management model was developed at Siemens Industrial Turbines in Finspång, Sweden and was first presented in Cronemyr (2007). The company - first under the owners ALSTOM and later Siemens - had implemented Six Sigma as process improvement methodology. The first author was one of the first Black Belts and one of very few who participated in the company's Six Sigma introduction twice, under two different company names. The first author who also had previous background in Quality and Process Management activities at Saab, ABB and university, realized that the rather advanced process improvement method of Six Sigma required established processes to work. Otherwise it would fail. It did so in most departments and divisions where processes had not been established but a few divisions started all-over, established processes and then introduced Six Sigma once more. It was a success (Cronemyr, 2007). When the success was a fact the company tried to share the best practice and use the same strategy at other departments. It was then realized that a pre-requisite for establishing processes was missing; process awareness in management. In some departments management workshops were 
conducted to train managers in systems thinking and Process Management principles. After that they could start establishing processes. By that time Lean had been introduced at some divisions and was integrated in the process work in a qualitative approach. Some divisions stayed on the more advanced quantitative approach and introduced Six Sigma successfully. One division later continued with the next step of basing decisions on facts and utilizing control variables identified in Six Sigma projects, by implementing Statistical Process Control for major business processes. The model that had been developed mainly at one company - during several years was later used at several other companies in Process Management consultancy assignments and interventions, see Figure 1.

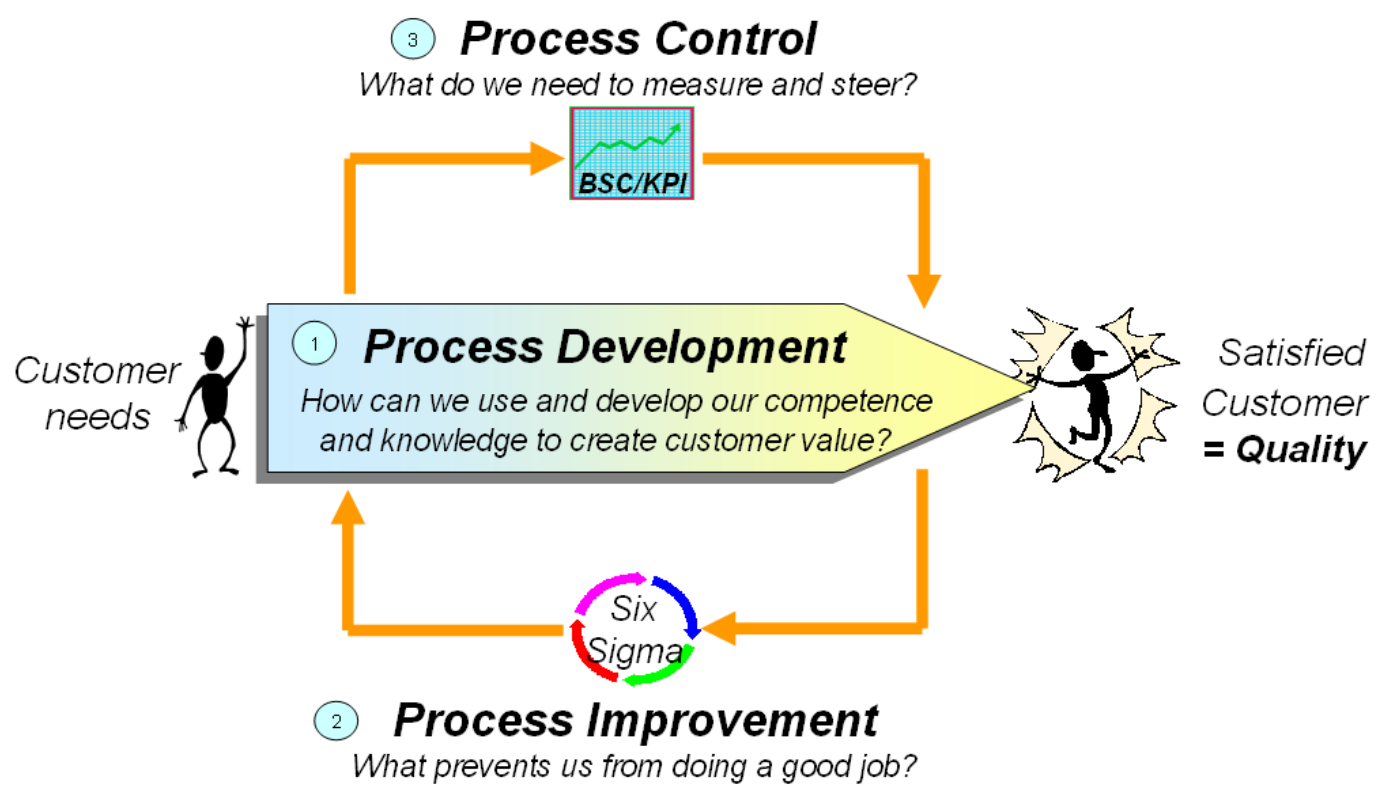

Figure 1. Process Management 1-2-3 (Cronemyr, 2007) 
The model is a framework for implementing and utilizing Process Management in the following steps (steps 1-2-3 are indicated in the figure):

0) Establishing process awareness in management,

1) Process mapping and development,

2) Process analysis and improvement, and

3) Process control and agility.

By taking these steps, you reach more advanced maturity levels, see below.

\section{Process Maturity Model}

The basic idea for the process maturity model, see Figure 2, was mainly developed from the first author's experiences from implementing Process Management in organizations and CMM (Paulk et.al., 1993), ideas about a maturity model to describe the progress. It was then further developed by several practical studies and by including the work of other authors e.g. Harrington (1991), Wheeler (1997), and McCormack (2007). The main contribution with our maturity model is that it provides a natural development path that organization can follow by its close link to 'Process Management 1-2-3' and its focus on success factors for achieving sustainable process work. This approach is not the same as McCormack’s (2007), since it does not focus on the balance between functions and processes. Our approach rather sees functions and processes as two necessary but separate dimensions of an organization. The levels in our model are also adapted to include the whole range from a complete lack of process thinking to fully adapted and controlled processes. This to make it useful in a wider spectrum of cases than the model described by Harrington (1991) 


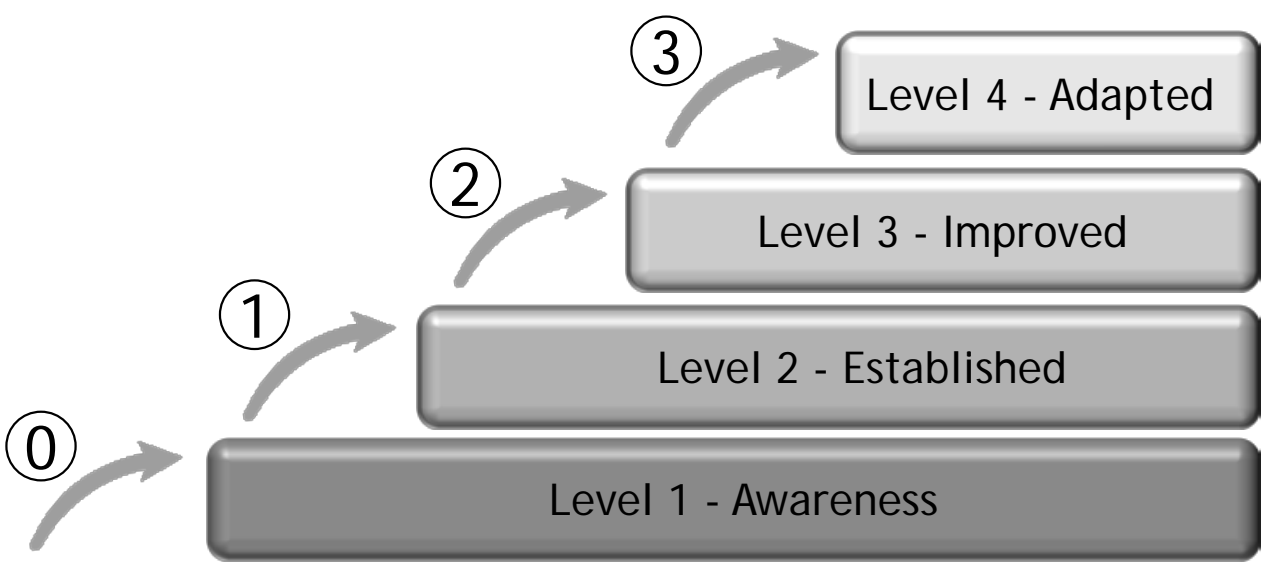

Business Need

Figure 2. The process maturity model. (Bergholtz and Danielsson, 2012).

When a process has reached maturity level $\mathrm{N}$, you need to take step $\mathrm{N}$, in order to reach maturity level $\mathrm{N}+1$. Hence there are three steps and four levels

In order to make the concept of process maturity possible to use by organizations who want to improve their processes, the model focuses on separate processes instead of whole organizations. The organizational focus used by McCormack (2007) can only show an average oversight of all of the organizations processes and hence not any detailed information. However, organizational factors have major impact on each process within the organization, and for the lower maturity levels where there are no established processes these factors are dominant. This is similar to Wheeler's (1997) approach, where the focus shifts from the product perspective to the process perspective when processes are established.

The model consists of four maturity levels and one 'pre-level', which describes the state when none of the maturity levels are reached. One level acts as the foundation for the next one, and the model thereby describes natural steps for implementing 
Process Management. An illustration of the maturity model is shown in Figure 2 and it is described in short in the following text.

Pre-level - Business need

This level is not considered to be a part of the maturity scale, since it is not a foundation for the other levels. The pre-level is rather considered to symbolize a lack of maturity, when none of the maturity levels are fulfilled. There exist no processes, the organization is functionally oriented and there is no process awareness within management. The organization does not have the necessary pre-requisites to establish processes.

\section{Level 1 - Awareness}

At this level the organization has gained an awareness of the usefulness of working with processes, mainly at a management level. There is no fully established process at this level, but there might be some process influences in the way of working. The awareness is necessary to obtain the commitment needed to establish sustainable processes.

\section{Level 2 - Established}

At this level the process is fully established in the organization. There may be one or more processes established but this maturity level and levels above deal with the maturity of one process at a time. The process is defined with all required constituents, it is documented and it is used in practice. For the process to be sustainable it is also required that management is active and actually gives the process attention and demands results from the process. Furthermore there need to be established structures to maintain and update the process. 


\section{Level 3 - Improved}

At this level the focus switches from the process map to process data. The process needs to be fully established in order to improving it. Otherwise there is no stable baseline from which to improve. Improvements should further be based on facts, which require developed and customer focused measurements and structured methods for conducting the improvement. In addition to measuring results, controls should be developed and established.

\section{Level 4 - Adapted}

For a process to be adapted it needs to work in closer collaboration with the customer, to be more flexible and to be more proactive. By implementing statistical process control it is possible to react to changes much sooner and to tune the process in a better way. The process should also be able to adapt to specific customer requirements by working closer to the customer or even including the customer in the process. This requires high commitment and understanding by everyone who uses the process.

\section{Diagnostics Tool}

In order to make the process maturity model more useful in practice, a diagnostics tool was developed. The purpose of the tool is to determine which level in the maturity model a certain process fulfills. To know the current status of the process is the basis for future improvements. Focus is hence not to get the most accurate diagnosis of which level a process fulfills, but to compile a comprehensive overview of the process maturity in a quick and resource efficient way. This differs from the methods used in CMM (Paulk et.al., 1993) and by Harrington (1991) which have a higher focus on accuracy, but also require a lot more work than the suggested method. It is also much richer in information than McCormack's (2007) method, which makes 
the results from the diagnosis more useful for the examined process. The first step toward creating our diagnostics tool was to develop the model further and break down the levels to more detailed components.

From the practical studies, basic process theory and Process Management models, e.g. Harrington’s model used at IBM (Harrington, 1991), eight process maturity categories were derived.

The categories are:

- Management of the organization which describes the process awareness and commitment within the management,

- Way of working treats how the processes and the process 'thinking' actually are applied in practice,

- Layout of the process deals with the basic constituents that defines a process,

- Documentation deals with how the process is described and how this description is used in practice,

- Management of the process treats how management and administration of the process are organized,

- Users of the process deals with the understanding and commitment from the people who actually use the process,

- Measurements describe how the process is controlled and how the results are measured, and finally

- Improvements describe how the process is maintained, updated and improved. 
These eight categories were then used to describe the maturity model in a new and more detailed way. Each maturity level was divided according to the categories and the state of the category was described for each level. These descriptions can also be seen as the criteria to determine whether a maturity level is achieved or not. For some of the maturity level-category combinations there are no criteria defined. When that is the case, the same criteria as for the previous level apply. If there is no previous level, as is the case for level 1 , there are no criteria to be met within the category to achieve the maturity level. See Figure 3.

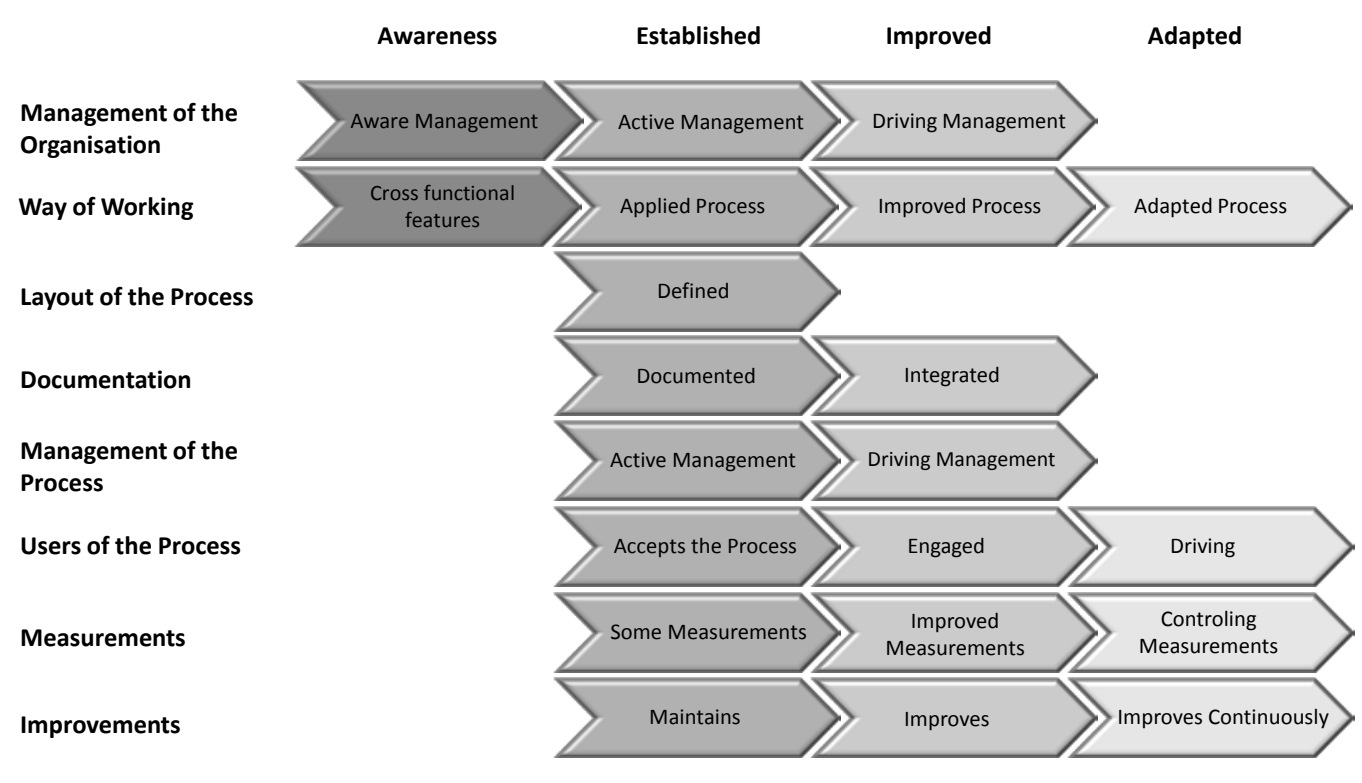

Figure 3. The detailed process maturity model, used as a basis for the diagnostics tool. (Bergholtz and Danielsson, 2012).

To determine if a process fulfills the criteria for each level, two separate questionnaires were developed. One aimed at persons who manage the process, e.g. process owners, and one aimed at process users. This to get more than one perspective of the process and to be able to cover all necessary aspects needed to describe the 
process. The questionnaires have about 40 questions each and cover several aspects within each of the different categories. The questions have pre-determined answering alternatives to make sure that the interpretation of the answers can be made in an unbiased way. The detailed questionnaires are not further presented in this paper.

The interpretation of the questionnaires is made with a template that indicates which answers are required or not accepted for each category and maturity level. Since the results of this type of questionnaire are discrete variables, it would not be correct to construct a mean from results of an extensive number of questionnaires. Instead we found it suitable to hand out the questionnaires to a small number of persons and then compile the separate results in a combined overview. The total process maturity is determined by the category which is considered to be the weakest link. With this approach, the overview will contribute with necessary information to plan and prioritize future improvement initiatives in order to increase the total process maturity. An example is given in Figure 4.

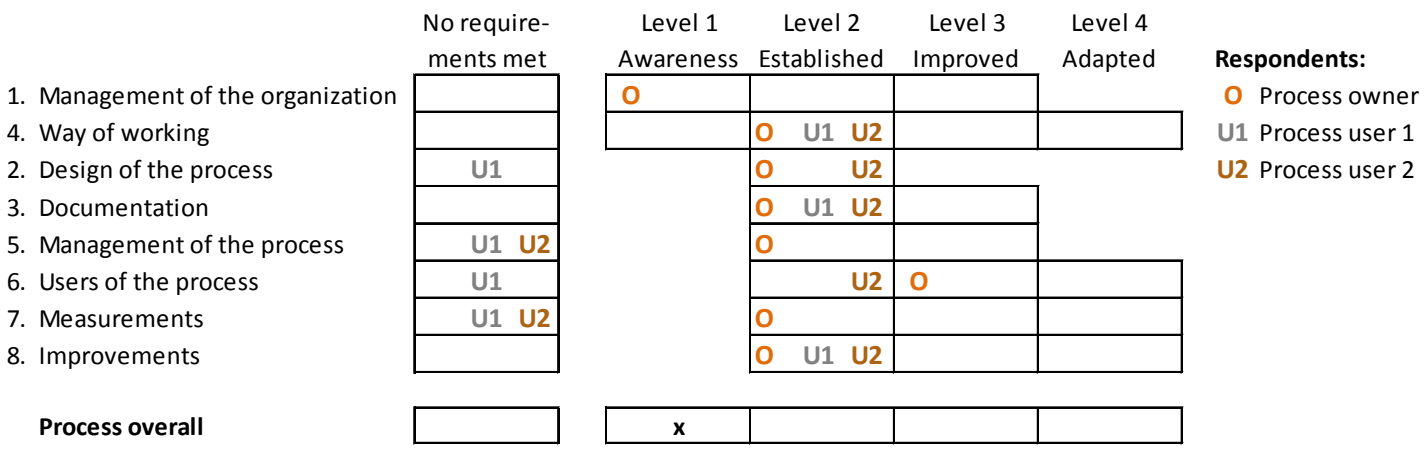

Figure 4. An example of the overview from questionnaires about a process.

(Bergholtz and Danielsson, 2012). 
The example shows an overview of the results from three respondents for a surveyed process at an industrial organization. As seen, most of the answers fulfill the requirements for level 2 for the different categories. However, there are some categories, e.g. Measurements, Management of the process and Management of the organization, which do not seem to reach as high as the other categories. Since the total process maturity is determined by the weakest link, the process overall is considered to reach level 1 . These areas are hence where future improvements should focus in order to increase the total process maturity. It can also be interesting to display the spread of the answers within the categories. In the category Users of the process all three respondents indicate different maturity level. This shows that there probably are very different levels of understanding and commitment among the users of the process.

The model and diagnostics tool was used in practice with five different processes at three different organizations in the study conducted by Bergholtz and Danielsson (2012). The surveyed organizations considered the results to be very accurate and useful for the future improvements of the involved processes.

\section{Discussion}

\section{Research limitations and implications}

This research is based on applications in a typical Scandinavian management culture, a so-called 'fulfilment-oriented culture', which is characterized as egalitarian and person-oriented (Trompenaars, 1993). Whether the proposed process maturity model will work in other cultures and if so how to organize the work in that type of setting remains to investigate. Furthermore, given that this study was conducted as action research, there are limitations concerning generalizability but, as generalizability is 
not the main purpose of action research, the outcome of the applications were successful for the participating organizations in this particular project. Given these limitations, more applications in other settings would be valuable in providing more generalizable results.

Still, it is our opinion that this paper fills a gap in management research literature between 'success criteria' and 'practical tools and results' for implementing Process Management. More research is needed on how to assess process maturity and where different QM tools fit and where they do not in a Process Management context.

\section{Managerial implications}

Organizations implementing Process Management sometimes start off on a 'too advanced' level with some of the more advanced tools and techniques without having fulfilled the necessary prerequisites. In fact, it is often unknown to the organizations that there are necessary prerequisites and what these are. The Process Management maturity model and the diagnostics tool presented in this paper will help organizations to reduce their risk of starting off 'too high' and thus failing in their efforts.

This model and tool have been developed together with several companies which benefitted from their use. One reason it is appreciated by users is that the diagnostics tool is considered 'objective' by the users, because the organizations perform the assessment themselves, without any direct influence from consultants. Consultants are often considered 'subjective' when they suggest appropriate actions for the company. Of course no one is objective but this tool gives a hint on where to start and what actions could be the logical next step for a company, wanting to implement Process Management. The outcome is used to plan and prioritize actions. Some companies have also suggested using it as a follow-up tool. 
It should be emphasized though that this is not a 'certification' or 'award' tool, like e.g. Malcolm Baldridge National Quality Award (see e.g. Bergman and Klefsjö, 2010). The main purpose of this tool is not to certify organizations, but to improve processes.

Process Management is a way of organizing quality work in order to improve customer satisfaction and reduce internal costs, and thus improve the company profit. It is our opinion that the presented model will help in that effort, by providing guidance of appropriate actions based on the process maturity.

\section{References}

Antony, J. and Banuelas, R. (2002) Key ingredients for the effective implementation of Six Sigma programme, Measuring Business Excellence, Vol. 6 pp. 20-27.

Beer, M. (2003). Why total quality management programs do not persist: The role of management quality and implications for leading a TQM transformation. Decision Sciences, 34(4), 623-642.

Beer, M. and Nohria, N. (2000) Cracking the code of change. Harvard Business Review, Vol 78 No. 3, pp. 133-141

Bergholtz, A. and Danielsson, M. (2012) Utveckling av en processmognadsmodell med tillhörande diagnosverktyg. Master Thesis. Quality Technology and Management, Department of Management and Engineering, Linköping University

Bergman, B., \& Klefsjö, B. (2010). Quality from Customer Needs to Customer Satisfaction. (Third edition). Studentlitteratur. 
Cronemyr, P. (2007). Six Sigma Management. Ph.D. Thesis. Division of Quality Sciences, Department of Technology Management and Economics, Chalmers University of Technology.

Cronemyr, P., \& Witell, L. (2010). Changing from a product to a process perspective for service improvements in a manufacturing company. The TQM Journal, 26-40.

Dahlgaard, J., Pettersen, J. and Dahlgaard-Park, S. M. (2011). Quality and lean health care: A system for assessing and improving the health of healthcare organisations. Total Quality Management \& Business Excellence, 22:6, 673-689.

Dahlgaard-Park, S. M. (2011). The quality movement: Where are you going? Total Quality Management \& Business Excellence, 22:5, 493-516.

Goldstein, M. D. (2001) Six Sigma programme Success Factors, Six Sigma Forum Magazine, Vol. 1, pp. 36-45.

Green, J. (2012). TQM and organisational culture: How do they link? Total Quality Management \& Business Excellence, 23:2, 141-157.

Hammer, M. (2002) Process management and the future of Six Sigma. MIT Sloan Management Review. Vol. 43e No. 2

Hammer, M. and J. Champy (1993). Reengineering the Corporation: a Manifesto for Business Revolution. New York, Harper Business.

Harrington, H. J. (1991). Business Process Improvement. New York: McGraw-Hill.

Hellström, A. (2006) Conceptions Of Process Management - An Analysis Of The Discourse In The Management Literature. In the proceedings from QMOD Liverpool. 
Hellström, A. (2007) On the Diffusion and Adoption of Management Ideas: Findings from six empirical studies in the quality field. Ph.D. thesis. Division of Quality Sciences. Chalmers University of Technology

Henderson, K. M. and Evans, J. R. (2000) Successful implementation of Six Sigma: benchmarking General Electric Company, Benchmarking: An International Journal, Vol. 7, pp. 260-281.

Kaplan, R. S. and Norton, D. P. (1992) The Balanced Scorecard - Measures that drive performance. Harvard Business Review, January-February.

Langstrand, J. (2012) Exploring organizational translation. A case study of changes toward Lean Production. Ph.D. Thesis. Quality Technology and Management. Department of Management and Engineering. Linköping university.

McCormack, K. (2007). Business Process Maturity. Lexington, KY.

Melan, E. H. (1995). Process Management - a systems approach to total quality. Portland: Productivity Press.

Oakland, J. S. and Tanner, S. (2007). Successful Change Management. Total Quality Management \& Business Excellence, 18:1-2, 1-19.

Pande, P.S., Neuman, R.P. and Cavanagh, R.R. (2000) The Six Sigma Way: How GE, Motorola and Other Top Companies are Honing their performance, New York, NY: McGraw-Hill Professional.

Paulk, M. C., Curtis, B., Chrissis, M. B., and Weber, C. V. (1993) Capability Maturity Model, Version 1.1. IEEE Software, Vol. 10, No. 4, July, pp. 18-27.

Rentzhog, O. (1998). Processorientering - en grund för morgondagens organisationer. Lund:Studentlitteratur. 
Sandholm, L. and Sörqvist, L. (2002) 12 Requirements For Six Sigma Success, Six Sigma Forum Magazine, Vol. 2, pp. 17-22.

Schön, K. (2006) Implementing Six Sigma in a non-American culture, Int. J. Six Sigma and Competitive Advantage, Vol. 2, No. 4, pp. 404-428.

Shewhart, W. A. (1931) Economic control of quality and manufactured product. Van Nostrand, New York.

Shewhart, W. A. (1939) Statistical method from the viewpoint of quality control. Graduate School of the Department of Agriculture, Washington D. C.

Sveningsson, S. and Sörgärde, N. (2007) Organisationsförändring: från ingenjörskonst till tolkning., in Alvesson, M. and Svenningsson, S. (Eds.), Organisationer, ledning och processer, Lund, Studentlitteratur.

Trompenaars, F. (1993) Riding the waves of culture: Understanding Cultural diversity in Business. New York, NY: McGraw-Hill Professional.

Westlander, G. (1998) Aktionsforskning (in Swedish; English translation: Action research). Research report, Royal Institute of Technology. Stockholm.

Wheeler, D. (1997). The four possibilities for any process. Quality Digest . 